\title{
CULTURA DE INTEGRIDADE EM PESQUISA: SOMOS AGENTES PROMOTORES
}

Editorial

A Revista Brasileira em Promoção da Saúde (Brazilian Journal in Health Promotion), movida pela necessidade de uma cultura que estimule a integridade em pesquisa, quer enfatizar sua preocupação, não apenas com o conteúdo de suas publicações, mas também com os aspectos éticos que envolvem a submissão e a publicação dos manuscritos. Com isso, pretende levantar a discussão sobre boas práticas em pesquisa científica, ressaltando a importância de que este reforço ocorra desde os primeiros estágios da carreira dos pesquisadores.

As más condutas éticas ocorrem em virtude das exigências crescente de produção intelectual e consequentemente as pressões sobre os pesquisadores vinculados aos programas de pós-graduação que utilizam os indicadores, principalmente, internacionais ${ }^{(1)}$. A proliferação destas condutas antiéticas também é influenciada pelo "sistema de recompensas" existente, no qual o pesquisador é avaliado pela sua produtividade.

O primeiro evento mundial sobre a integridade em pesquisa ocorreu em 2007 na cidade de Lisboa ${ }^{(2)}$ e buscou sensibilizar a comunidade científica e editores para a importância de promover a conduta responsável na pesquisa. Em 2010, houve a segunda conferência mundial em Singapura ${ }^{(3)}$. Desta conferência emergiu a "Declaração de Singapura sobre integridade em pesquisa" trazendo como princípios de integridade: a honestidade, a responsabilidade, o respeito e imparcialidade profissionais e a boa gestão da pesquisa ${ }^{(3)}$. Em 2013, a terceira edição ocorreu em Montreal e teve como grande linha temática as investigações que cruzam as fronteiras e as parcerias internacionais ${ }^{(4)}$.

A exemplo destes movimentos internacionais, o Brasil também se mobilizou. Entretanto, esta preocupação é recente e tomou corpo após séries de publicações a respeito desta temática elaborado pela Fundação de Amparo à Pesquisa do Estado de São Paulo (FAPESP) ${ }^{(5)}$ e pela publicação do Relatório da Comissão de Integridade de Pesquisa do Conselho Nacional de Desenvolvimento Científico e Tecnológico $(\mathrm{CNPq})^{(6)}$.

Paralelo a estas publicações, dois importantes eventos ocorreram nos anos de 2011 e 2012 no Brasil que abordaram ações para promoção da integridade científica norteando pesquisadores e instituições brasileiras, o I e II Brispe (Brazilian Meeting on Research Integrity, Science and Publication Ethics) $)^{(7)}$. Neste ano de 2015, o Brasil sediará a " 4 a Conferência Anual para Integridade da Pesquisa" (4 $4^{\text {th }}$ World Conference on Research Integrity) no Rio de Janeiro, que irá explorar a "excelência da investigação científica em seus diferentes sistemas”(8).

Somado a estes movimentos nacionais, destacamos a importância de que os periódicos científicos discutam suas políticas editoriais com a comunidade científica para exercermos o papel de educador das boas práticas em pesquisa e prevenir as más condutas, como plágio, autoplágio, fraude, autoria indevida, entre outros.

Dentre estes, o plágio vem ganhando destaque no cenário internacional em virtude do crescente número de relatos deste tipo de má conduta. No Brasil, a situação é preocupante, calcula-se a proporção disto quando renomado pesquisador 
da área afirma "o Brasil encontra-se entre os vinte países com o maior índice de ocorrência de plágio e de redundância (autoplágio) o que foi constatado por meio de uma amostra de artigos publicados na PubMed entre 2008 e 2012"(8,p.1).

Nas diretrizes do $\mathrm{CNPq}^{(6)}$, considera-se plágio:

“...apresentação, como se fosse de sua autoria, de resultados ou conclusões anteriormente obtidos por outro autor, bem como de textos integrais ou de parte substancial de textos alheios sem os cuidados detalhados nas Diretrizes.”

Em consonância com estes movimentos, a Associação Brasileira de Editores Científicos (ABEC) promove eventos e lança textos de pesquisadores renomados no intuito de manter constante debate sobre a qualidade e consolidação das publicações/periódicos editados no país, seguindo os padrões internacionais de editoração e ética.

Por fim, as más condutas na pesquisa são assunto de interesse das revistas científicas, que devem implantar mecanismos que permitam identificar e desestimular as práticas fraudulentas na pesquisa e estimular sua integridade.

Movida por este desejo, a Revista Brasileira em Promoção da Saúde institui, neste ano de 2015, uma política de submissão/avaliação dos manuscritos que envolverá, além da inclusão de dois documentos obrigatórios, o parecer de aprovação do projeto em comitê de ética em pesquisa com seres humanos ou com animais e a declaração de autoria, a utilização de programa antiplágio em todos os manuscritos submetidos para análise, e com isso, almeja educar autores e proliferar a ideia de que os artigos publicados estão em consonância com a ética e integridade mundiais.

\section{REFERÊNCIAS}

1. Shinkai RS. Integridade na pesquisa e ética na publicação. Sci Med. 2011;21(1):2-3.

2. Russo M. Ética e integridade na ciência: da responsabilidade do cientista à responsabilidade coletiva. Estud Av. 2014;28(80):189-98.

3. World Conference on Research Integrity. Singapore Statement on Research Integrity [Internet]. Singapore [cited 2015 Feb 10]. Available from: http://www. singaporestatement.org/downloads/singpore $\% 20$ statement_A4size.pdf

4. World Conference on Research Integrity. Montreal Statement on Research Integrity in CrossBoundary Research Collaborations [Internet]. Montreal; [cited 2015 Feb 03]. Available from: http://www.researchintegrity.org/3wcri/doc-pdf/ MontrealStatement.pdf

5. Fundação de Amparo à Pesquisa do Estado de São Paulo - FAPESP. Código de boas práticas científicas [Internet]. São Paulo: FAPESP; 2014 [acesso em 2015 Jan 26]. Disponível em: http://www.fapesp.br/ boaspraticas/FAPESP-Codigo_de_Boas_Praticas Cientificas_2014.pdf

6. Conselho Nacional de Desenvolvimento Científico e Tecnológico - CNPQ. Comissão de integridade na atividade científica [Internet]. Brasília: CNPQ; 2012 [acesso em 2015 Jan 26]. Disponível em: http:// www.cnpq.br/web/guest/view/-/journal_content/56 INSTANCE_0oED/10157/106200

7. Brazilian Meeting on Research Integrity, Science and Publications Ethics - BRISPE [Internet]. Rio de Janeiro: UFRJ; 2012 [acesso em 2015 Fev 02]. Disponível em: http://www.iibrispe.coppe.ufrj.br

8. Farré E. A integridade da pesquisa no centro das atenções Elsevier [Internet]. Elsevier; 2015 [acesso em 2015 Fev 02]. Disponível em: http://americalatina. elsevier.com/sul/elseviernews/25/pt/completo25.pdf

9. Krokoscz M. Plágio na publicação científica brasileira [Internet]. São Paulo: ABEC; 2015 [acesso em 2015 Abr 02];1(3):1. Disponível em: http://www.abecbrasil org.br/newsletter/news03_ano01.html

\section{Endereço para correspondência:}

Ana Paula Vasconcellos Abdon

Universidade de Fortaleza

Av. Washington Soares, 1321

Bairro: Edson Queiroz

CEP: 60.811-905 - Fortaleza - CE - Brasil

E-mail:paulaabdon@unifor.br 